\title{
A historical misleading case of erythema ab igne in a young female patient
}

\section{Ghita Senhaji, Ouiame El Jouari, Zakia Douhi, Fatima Zahra Mernissi}

Department of Dermatology, University Hospital Hassan II, Fez, Morocco

Corresponding author: Dr Ghita Senhaji, E-mail: ghitasenhaji88@gmail.com

Erythema ab igne is a persistent, chronic skin condition resulting from extended exposure to low grade heat [1]. It's usually asymptomatic, though some patients report itching or burning at the site [2]. Clinically, it is characterized by reticular, brownish pigmented, often telangiectatic lesions on the areas of heating exposure, commonly mistaken for livedo reticularis [3]. The prognosis is good with removal of the offending heat source typically resulting in a gradual regression of the hyperpigmentation [1]. Herein we present a historical case of erythema $a b$ igne in a young female patient with history of chronic leg exposure to radiator heat.

A 29 year old female patient with history of hypertension and chronic renal failure, presented to the nephrology department for a surge of her disease requiring a hemodialysis session. She reported a history of painless and non-pruriginous hyperpigmented networked discolorations over her antero internal leg faces, which

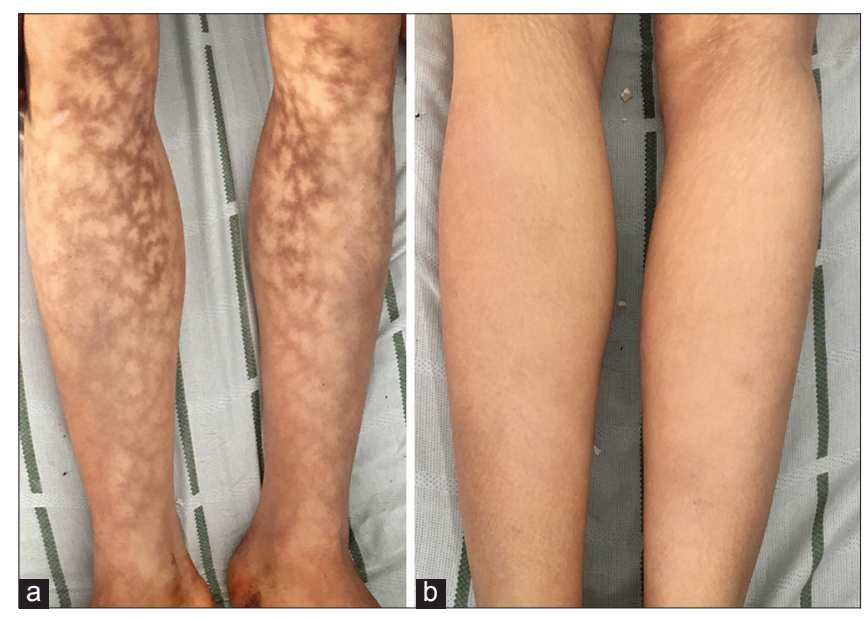

Figure 1: Erythema ab igne. (a): Clinical image showing a large, hyperpigmented, dark brown, reticular patch, localized over the internal leg faces. (b): Normal clinical aspect of posterior faces of the legs. have been persistent for l year, with no functional signs. Clinical examination revealed a large, hyperpigmented, dark brown, reticular patch without telangiectasias nor erythema, spread diffusely over her internal leg faces (Figs. la and lb). The patch was non infiltrated and non purpuric.

Dermoscopy examination found a diffuse brown hyperpigmetation without telangiectasias or erythema (Fig 2). There was neither pruritus nor pain. After meticulous questioning, the patient confirmed the area of hyperpigmentation corresponded to the area of heating exposure. Given this history and the physical findings with lack of systemic inflammation on biological testings, an underlying livedo reticularis was excluded and the diagnosis of erythema ab igne was made. The patient was then educated to avoid close and prolonged exposure to the offending heat source.

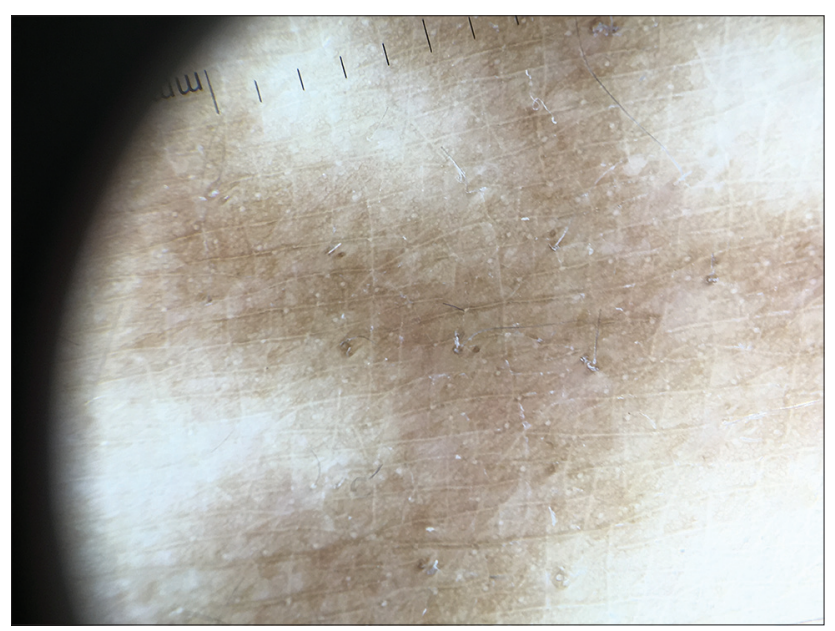

Figure 2: Erythema ab igne. Dermoscopic image showing a diffuse brown hyperpigmentation without purpura or telangiectasias.

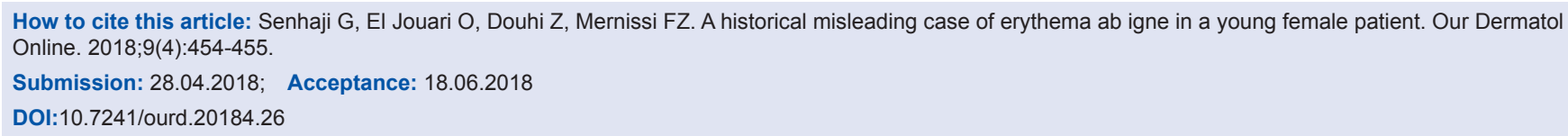


www.odermatol.com

\section{CONSENT}

The examination of the patient was conducted according to the Declaration of Helsinki principles.

\section{REFERENCES}

1. Salgado F, Handler MZ, Schwartz RA. Erythema ab igne: new technology rebounding upon its users? Int J Dermatol. 2018;57:393-6.

2. Redding KS, Watts AN, Lee J, Kennedy KR, Shimek CM, Skinner RB.
Space heater-induced bullous erythema ab igne. Cutis. 2017;100:E9-10.

3. Gmuca S, Yu J, Weiss PF, Treat JR, Sherry DD. Erythema Ab Igne in an Adolescent with chronic Pain: An Alarming Cutaneous Eruption From Heat Exposure. Pediatr Emer Care. 2018 Mar 12. doi: 10.1097/PEC.0000000000001460. [Epub ahead of print]

Copyright by Ghita Senhaji, et al. This is an open-access article distributed under the terms of the Creative Commons Attribution License, which permits unrestricted use, distribution, and reproduction in any medium, provided the original author and source are credited.

Source of Support: Nil, Conflict of Interest: None declared. 